\title{
Canopy Optical Indices from Infinite Reflectance and Canopy Reflectance Models for Forest Condition Monitoring: Application to Hyperspectral CASI Data
}

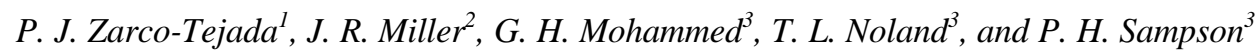 \\ ${ }^{1}$ Centre for Research in Earth and Space Science (CRESS), York University and ${ }^{2}$ Dept. of Physics and Astronomy, York \\ University \& Centre for Research in Earth and Space Technology (CRESTech), 4700 Keele Street \\ Toronto, Ontario M3J 1P3, Canada - e-mail:pzarco@yorku.ca \\ ${ }^{3}$ Ontario Forest Research Institute (OFRI). Ontario Ministry of Natural Resources, 1235 Queens St. E., Sault Ste. Marie, \\ Ontario P6A 2E5, Canada
}

\begin{abstract}
This paper reports on progress made to link physiologicallybased indicators to optical indices from hyperspectral remote sensing. This study is carried out on twelve sites of Acer saccharum M. in the Algoma Region, Ontario (Canada), where field measurements and hyperspectral CASI imagery have been collected in 1997 and 1998 deployments. Individual tree samples were collected at each site for biochemical analysis and measurement of leaf chlorophyll, chlorophyll fluorescence and carotenoid concentrations, as well as leaf reflectance and transmittance. Physiological indices and derivative analysis indices extracted from leaf spectral reflectance have been tested at canopy level using CASI data of 72 channels and $2 \mathrm{~m}$ spatial resolution at 3 simulation scales which progressively more closely represent the observed above-canopy reflectance spectra from the sites: single leaf reflectance data, infinite reflectance calculated from optically-thick leaf simulation formulae, and canopy reflectance models using nominal site canopy architecture data. This study shows that selected algorithms connecting leaf reflectance and transmittance data to corresponding bioindicators at the leaf level can be expressed at canopy level through canopy models yielding predictions of bioindicators in airborne imaging spectrometer with coefficients of determination as high as 0.91 .
\end{abstract}

\section{INTRODUCTION}

The aim of the Bioindicators of Forest Sustainability Project [1][2] is to develop links between physiologically-based bio-indicators (e.g. pigment concentrations, chlorophyll fluorescence) from field and laboratory data and optical indices from hyperspectral remote sensing for assessing forest condition. This paper reports on results from 12 sites of Acer saccharum M. (sugar maple) in the Algoma Region, Ontario (Canada), where field measurements and hyperspectral CASI imagery have been collected in 1997 and 1998 field campaigns.

\section{DATA COLLECTION}

The CASI data acquisition was divided into three missions depending on the sensor mode of operation, i.e. mapping mission, with $0.5 \mathrm{~m}$ spatial resolution and 5 spectral bands; the hyperspectral mission, with $2 \mathrm{~m}$ spatial resolution, 72 channels and $7.5 \mathrm{~nm}$ spectral resolution; and the full-spectral hyperspectral mission, with 288 channels and $2.5 \mathrm{~nm}$ spectral resolution. Crown cover and LAI measurements were acquired for all the plots using hemispherical photography, a PCA LiCor-2000 and a spherical densiometer. A total of 440 single leaf samples were collected at each site for biochemical analysis and measurement of leaf chlorophyll, chlorophyll fluorescence and carotenoid concentrations. The ratio of variable to maximum chlorophyll fluorescence $(\mathrm{Fv} / \mathrm{Fm})$, a measure of photosynthetic efficiency [3], was measured in all leaf samples. Single leaf reflectance and transmittance measurements were acquired on all leaf samples using a Li-Cor 1800 Sphere apparatus with an Ocean Optics fibre spectrometer with $0.5 \mathrm{~nm}$ spacing and $7.5 \mathrm{~nm}$ spectral resolution in the $400-900 \mathrm{~nm}$ range. A signal-to-noise study was carried out in order to choose the optimum passbands for the smoothing and derivative processing to be applied to the single leaf reflectance and transmittance measurements. It was found that reflectance spectra were optimally smoothed with an order-3 SavitzkyGolay algorithm with $25 \mathrm{~nm}$ bandwidth; for the calculation of derivative spectra a $13 \mathrm{~nm}$ bandwidth was selected using the same Savitzky-Golay polynomial fit algorithm.

The 12-bit radiometric resolution data collected by CASI was processed to at-sensor radiance using calibration coefficients derived in the laboratory by CRESTech. Aerosol optical depth data at $550 \mathrm{~nm}$ were collected in the study area at the time of data acquisition in order to process image data to ground-reflectance using the CAM5S atmospheric correction model. Reflectance data were afterwards georeferenced using GPS data collected onboard the aircraft. Final registration of the hyperspectral mode imagery was achieved by registration to the mapping mission CASI imagery using visual identification of ground-referenced $1 \mathrm{~m}$ white targets, which served to identify the location of the sites.

\section{SELECTION OF OPTICAL INDICES}

Candidate optical indices from reflectance and derivative spectra were identified and grouped into 4 categories, based on the spectral region and the type of parameters used: 
(a) Visible Ratios: SRPI $\left(\mathrm{R}_{430} / \mathrm{R}_{680}\right) ; \quad$ NPQI $\left(\mathrm{R}_{415}-\mathrm{R}_{435}\right) /\left(\mathrm{R}_{415}+\mathrm{R}_{435}\right)$; $\quad$ PRI calculated as $\left(\mathrm{R}_{531}-\mathrm{R}_{570}\right) /\left(\mathrm{R}_{531}+\mathrm{R}_{570}\right), \quad\left(\mathrm{R}_{550}-\mathrm{R}_{531}\right) /\left(\mathrm{R}_{550}+\mathrm{R}_{531}\right) \quad$ and $\left(\mathrm{R}_{570}-\mathrm{R}_{539}\right) /\left(\mathrm{R}_{570}+\mathrm{R}_{539}\right)$; NPCI $\left(\mathrm{R}_{680}-\mathrm{R}_{430}\right) /\left(\mathrm{R}_{680}+\mathrm{R}_{430}\right)$; Carter $\left(\mathrm{R}_{695} / \mathrm{R}_{420}\right), \mathrm{G}\left(\mathrm{R}_{554} / \mathrm{R}_{677}\right)$ and Lichtenthaler $\left(\mathrm{R}_{440} / \mathrm{R}_{690}\right)$.

(b) Visible/NIR Ratios: NDVI $\left(\mathrm{R}_{774}-\mathrm{R}_{677}\right) /\left(\mathrm{R}_{774}+\mathrm{R}_{677}\right)$; $\mathrm{SR}$ $\left(\mathrm{R}_{774} / \mathrm{R}_{677}\right)$; Lichtenthaler $\left(\mathrm{R}_{800}-\mathrm{R}_{680}\right) /\left(\mathrm{R}_{800}+\mathrm{R}_{680}\right),\left(\mathrm{R}_{440} / \mathrm{R}_{740}\right)$; Gitelson \& Merzylak $\left(\mathrm{R}_{750} / \mathrm{R}_{550}\right)$ and SIPI $\left(\mathrm{R}_{800}-\mathrm{R}_{450}\right) /\left(\mathrm{R}_{800}+\mathrm{R}_{650}\right)$.

(c) Red Edge Reflectance-Ratio Indices: Vogelmann $\left(\mathrm{R}_{740} / \mathrm{R}_{720}\right), \quad\left(\mathrm{R}_{734}-\mathrm{R}_{747}\right) /\left(\mathrm{R}_{715}+\mathrm{R}_{726}\right),\left(\mathrm{R}_{734}-\mathrm{R}_{747}\right) /\left(\mathrm{R}_{715}+\mathrm{R}_{720}\right)$; Gitelson \& Merzylak $\left(\mathrm{R}_{750} / \mathrm{R}_{700}\right)$; and Carter $\left(\mathrm{R}_{695} / \mathrm{R}_{760}\right)$.

(d) Spectral and Derivative Red Edge Indices: $\lambda_{\mathrm{p}}, \lambda_{\mathrm{o}}, \mathrm{R}_{\mathrm{o}}, \mathrm{R}_{\mathrm{s}}$ and $\sigma$ from red edge inverted-gaussian curve fitting, as well as spectral indices calculated from derivative analysis: $\left(\mathrm{D}_{715} / \mathrm{D}_{705}\right)$; DPR1 ( $\left.\mathrm{D}_{\lambda_{0}} / \mathrm{D}_{\lambda_{0}+12}\right)$, DPR2 ( $\left.\mathrm{D}_{\lambda_{0}} / \mathrm{D}_{\lambda_{0+22}}\right)$, DP21 $\left(\mathrm{D}_{\lambda_{0}} / \mathrm{D}_{703}\right)$ and DP22 $\left(\mathrm{D}_{\lambda_{0}} / \mathrm{D}_{720}\right)$, amongst others.

The optical indices were calculated at 3 scales which are expected to progressively more closely represent the observed above-canopy reflectance spectra of the sites:

(i) from single leaf reflectance data;

(ii) from infinite reflectance $\left(\mathrm{R}_{\infty}\right)$ data, calculated by using single leaf reflectance and transmittance data in optically-thick leaf simulation formulae; and

(iii) from canopy reflectance models using single leaf reflectance and transmittance data and nominal canopy architecture data.

In Equations (1) to (3), the optically-thick medium reflectance (denoted the infinite reflectance $R_{\infty}$ ) is related to the single leaf reflectance $r$ and the single leaf transmittance $t$, with single leaf absorptance $\alpha$ calculated as $\alpha=1-r-t$, by:

$$
\begin{aligned}
& \mathrm{R}_{\infty 1} \text { approx. leaf stack } \rightarrow \frac{R_{\infty}}{r}=\frac{1}{1-t^{2}} \\
& \mathrm{R}_{\infty 2} \text { leaf stack } \rightarrow \quad \frac{R_{\infty}}{r}=\frac{1}{1-\frac{2 t^{2}}{1+\left(1-4 t^{2}\right)^{1 / 2}}} \\
& \mathrm{R}_{\infty 3} \text { thick leaf } \rightarrow \\
& R_{\infty}=\frac{1-\alpha^{1 / 2}}{1+\alpha^{1 / 2}}
\end{aligned}
$$

In Equations (1) and (2) the infinite reflectances $\left(\mathrm{R}_{\infty 1}, \mathrm{R}_{\infty 2}\right)$ correspond to optically-thick stacks of leaves in which multiple reflectance between leaves is ignored [4], and in which multiple scattering is included (derived using the matrix formulation of Fujimura [5,6]). In Equation (3) the infinite reflectance $\left(\mathrm{R}_{\infty 3}\right)$ characterizes the optically-thick medium with the single-leaf absorption and scattering properties and assumes isotropic scattering [7].

For the application of the SAIL [8] and Kuusk [9] canopy reflectance models nominal input parameters derived from the study areas were used: $\mathrm{LAI}=3.5$, plagiophile leaf angle distribution function (LADF), soil reflectance data derived from imagery and model-estimated skylight irradiance fraction based on conditions during airborne acquisitions. Additional parameters needed in the Kuusk model were $\mathrm{n}=1.4, \mathrm{sl}=0.007 \& \theta^{*}=40^{\circ}$, and $\varepsilon=0.95 \& \theta_{\mathrm{m}}=45^{\circ}$ for the LADF for the assumed plagiophile leaf distribution function.

\section{RESULTS OF THE SIMULATION STUDY}

Results obtained at leaf level from measurements collected in June and July 1998 demonstrated that a link exists between leaf pigments, chlorophyll- $a$, chlorophyll- $a \& b$, carotenoids, leaf fluorescence and certain indices. The most promising indices at the individual leaf level are those listed in Table 1, along with their determination coefficients. Using single leaf reflectance and transmittance data as input, the same optical indices were calculated from $\mathrm{R}_{\infty}$ spectra from $(1,2,3)$ and through the SAIL and Kuusk canopy reflectance models. These simulated above-canopy optical indices and the corresponding measurements of bioindicators (pigments and fluorescence) from the 440 leaf samples permitted the derivation of prediction algorithms for site bioindicators.

Table 1. Determination coefficients $(r>0.6)$ obtained in the statistical analysis between chlorophyll- $a$, chlorophyll $\mathrm{a} \& b$, carotenoids and Fv/Fm, and optical indices obtained from Acer saccharum $\mathrm{M}$. leaf reflectance and transmittance measurements.

\begin{tabular}{|c|c|c|c|c|}
\hline Optical Index & $\begin{array}{c}r \\
c h l-a / \\
c m^{2}\end{array}$ & $\begin{array}{c}r \\
a \& b / \\
c m^{2}\end{array}$ & $\begin{array}{c}r \\
\text { caro/ } \\
c m^{2}\end{array}$ & $\begin{array}{c}r \\
C h F l \\
F v / F m\end{array}$ \\
\hline Vogelmann $\left(\mathrm{R}_{740} / \mathrm{R}_{720}\right)$ & 0.82 & 0.8 & 0.8 & 0.69 \\
PRI $\left(\mathrm{R}_{531}-\mathrm{R}_{570}\right) /\left(\mathrm{R}_{531}+\mathrm{R}_{570}\right)$ & - & - & - & 0.72 \\
PRI $\left(\mathrm{R}_{550}-\mathrm{R}_{531}\right) /\left(\mathrm{R}_{550}+\mathrm{R}_{531}\right)$ & -0.61 & -0.63 & - & -0.68 \\
PRI $\left(\mathrm{R}_{570}-\mathrm{R}_{539} /\left(\mathrm{R}_{570}+\mathrm{R}_{539}\right)\right.$ & - & - & - & -0.68 \\
Carter $\left(\mathrm{R}_{695} / \mathrm{R}_{760}\right)$ & -0.77 & -0.75 & -0.74 & -0.64 \\
Gitelson \& Merzylak $\left(\mathrm{R}_{750} / \mathrm{R}_{700}\right)$ & 0.82 & 0.8 & 0.8 & 0.66 \\
Vogelmann $\left(\mathrm{R}_{734}-\mathrm{R}_{747}\right) /\left(\mathrm{R}_{715}+\mathrm{R}_{726}\right)$ & -0.82 & -0.81 & -0.81 & -0.66 \\
Vogelmann $\left(\mathrm{R}_{734}-\mathrm{R}_{747}\right) /\left(\mathrm{R}_{715}+\mathrm{R}_{720}\right)$ & -0.83 & -0.81 & -0.81 & -0.66 \\
Lichtenthaler $\left(\mathrm{R}_{440} / \mathrm{R}_{690}\right)$ & 0.74 & 0.73 & 0.74 & 0.61 \\
$\lambda \mathrm{p}$ & 0.81 & 0.79 & 0.79 & 0.69 \\
DP22 $\left(\mathrm{D}_{\lambda 0} / \mathrm{D}_{720}\right)$ & -0.73 & -0.72 & -0.68 & -0.71 \\
Vogelmann $\left(\mathrm{D}_{715} / \mathrm{D}_{705}\right)$ & 0.82 & 0.79 & 0.79 & 0.69 \\
DP21 $\left(\mathrm{D}_{\lambda 0} / \mathrm{D}_{703}\right)$ & 0.82 & 0.79 & 0.79 & 0.65 \\
Gitelson \& Merzylak $\left(\mathrm{R}_{750} / \mathrm{R}_{550}\right)$ & 0.81 & 0.79 & 0.76 & - \\
$\mathrm{G}\left(\mathrm{R}_{554} / \mathrm{R}_{677}\right)$ & -0.74 & -0.72 & -0.71 & - \\
\hline
\end{tabular}




\section{APPLICATION TO CASI DATA}

CASI data were collected over the study sites within the same period of the field data acquisition. Mean reflectance values per plot were calculated in each Acer saccharum M. study site of $20 \times 20 \mathrm{~m}$. Data were acquired in the hyperspectral reflectance mode, with $2 \mathrm{~m}$ spatial resolution and 72 spectral channels. The mean reflectance per plot was calculated selecting the brightest $25 \%$ pixels in the NIR, therefore targeting crowns while minimizing influence of shadows, canopy openings and the direct understorey reflectance.

Table 2 shows the determination coefficients between measured and the estimated values of chlorophyll- $a$, chlorophyll- $a \& b$, carotenoids and leaf fluorescence $\mathrm{Fv} / \mathrm{Fm}$ derived by applying leaf simulation relationships obtained through $\mathrm{R}_{\infty}$ models and SAIL and Kuusk canopy reflectance models to CASI data collected over Acer saccharum M. study sites. Figure 1 shows the estimation of $\mathrm{Fv} / \mathrm{Fm}$ from a Vogelmann optical index $R_{740} / R_{720}$ [10] using $R_{\infty 1}, R_{\infty 2}$ and $\mathrm{R}_{\infty 3}$, and the SAIL and Kuusk CR models. It can be seen that the estimation improves when SAIL and Kuusk CR models are used. For all indices used the estimations improve (correlation slope progressively approaches unity) when the optical indices are calculated using first $\mathrm{R}_{\infty}$ and then canopy reflectance (CR) models. Figure 2 shows the excellent simulations with the Kuusk CR model (i.e. slope $=0.99$ ) when the index DP21 $\left(\mathrm{D}_{\lambda_{0}} / \mathrm{D}_{703}\right)$ is used to estimate Fv/Fm.

Table 2.- Determination coefficients $(r>0.4)$ obtained in chlorophyll- $a$, chlorophyll $\mathrm{a} \& b$, carotenoids and $\mathrm{Fv} / \mathrm{Fm}$ estimations applying relationships from $\mathrm{R}_{\infty 1}, \mathrm{R}_{\infty 2}$, and $\mathrm{R}_{\infty 3}$ optically-thick leaf simulation models and SAIL and Kuusk CR models to CASI data collected over Acer saccharum M. study sites.

\begin{tabular}{|c|c|c|c|c|}
\hline Optical Index & $\begin{array}{c}r \\
\text { chl-al } \\
\mathrm{cm}^{2}\end{array}$ & $\begin{array}{c}r \\
a \& b / \\
\mathrm{cm}^{2}\end{array}$ & $\begin{array}{c}r \\
\text { carol }^{2} \mathrm{~cm}^{2}\end{array}$ & $\begin{array}{c}r \\
C h F l \\
F v / F m\end{array}$ \\
\hline $\operatorname{DP} 21\left(\mathrm{D}_{\lambda_{0}} / \mathrm{D}_{703}\right)$ & 0.64 & 0.63 & 0.42 & 0.91 \\
\hline Vogelmann $\left(\mathrm{R}_{740} / \mathrm{R}_{720}\right)$ & 0.6 & 0.6 & - & 0.9 \\
\hline Vogelmann $\left(\mathrm{R}_{734} \mathrm{R}_{747}\right) /\left(\mathrm{R}_{715}+\mathrm{R}_{726}\right)$ & 0.61 & 0.6 & - & 0.87 \\
\hline Vogelmann $\left(\mathrm{R}_{734} \mathrm{R}_{-747}\right) /\left(\mathrm{R}_{715}+\mathrm{R}_{720}\right)$ & 0.61 & 0.61 & - & 0.87 \\
\hline Gitelson \& Merzylak $\left(\mathrm{R}_{750} / \mathrm{R}_{700}\right)$ & 0.45 & 0.44 & - & 0.84 \\
\hline Carter $\left(\mathrm{R}_{695} / \mathrm{R}_{760}\right)$ & - & - & - & 0.83 \\
\hline$\lambda_{p}$ & 0.56 & 0.56 & _ & 0.82 \\
\hline Vogelmann $\left(\mathrm{D}_{715} / \mathrm{D}_{705}\right)$ & 0.46 & 0.45 & 0.42 & 0.79 \\
\hline $\operatorname{DPR} 2\left(\mathrm{D}_{\lambda_{0}} / \mathrm{D}_{\lambda_{\mathrm{o}+22}}\right)$ & - & - & - & -0.68 \\
\hline Gitelson \& Merzylak $\left(\mathrm{R}_{750} / \mathrm{R}_{550}\right)$ & 0.45 & 0.44 & - & 0.67 \\
\hline $\mathrm{DP} 22\left(\mathrm{D}_{\lambda_{0}} / \mathrm{D}_{720}\right)$ & -0.55 & -0.54 & - & -0.63 \\
\hline PRI $\left(\mathrm{R}_{570}-\mathrm{R}_{539}\right) /\left(\mathrm{R}_{570}+\mathrm{R}_{539}\right)$ & - & - & - & 0.63 \\
\hline DPR1 $\left(\mathrm{D}_{\lambda_{0}} / \mathrm{D}_{\lambda_{\mathrm{o}+12}}\right)$ & - & - & - & -0.6 \\
\hline PRI $\left(\mathrm{R}_{531}-\mathrm{R}_{570}\right) /\left(\mathrm{R}_{531}+\mathrm{R}_{570}\right)$ & - & - & - & 0.59 \\
\hline PRI $\left(\mathrm{R}_{550}-\mathrm{R}_{531}\right) /\left(\mathrm{R}_{550}+\mathrm{R}_{531}\right)$ & 0.59 & 0.58 & - & - \\
\hline Lichtenthaler $\left(\mathrm{R}_{440} / \mathrm{R}_{690}\right)$ & 0.46 & 0.46 & - & - \\
\hline Carter $\left(\mathrm{R}_{695} / \mathrm{R}_{420}\right)$ & 0.46 & 0.47 & - & - \\
\hline $\mathrm{G}\left(\mathrm{R}_{554} / \mathrm{R}_{677}\right)$ & 0.46 & 0.44 & - & - \\
\hline
\end{tabular}

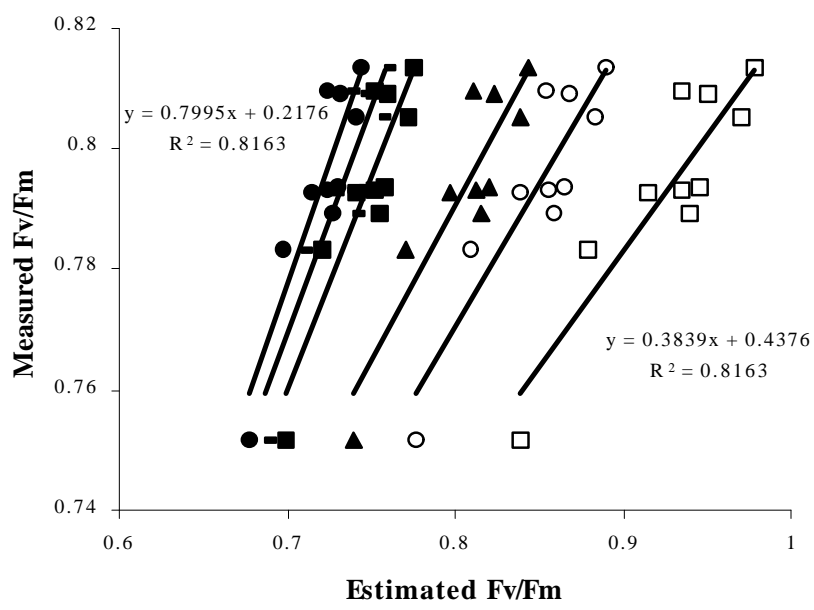

- Kuusk - Sail $\boldsymbol{\square} \Re 3 \Delta \Re \infty 2 \bigcirc \Re \infty 1 \square R f l$

Figure 1.- Estimation of $\mathrm{Fv} / \mathrm{Fm}$ from CASI data using the Vogelmann $\left(\mathrm{R}_{740} / \mathrm{R}_{720}\right)$ algorithm developed at leaf level through $\mathrm{R}_{\infty}$ and CR leaf simulation models. The data corresponds to Acer saccharum M. study sites.

An overview of the complete analysis methodology followed in this study is shown in Figure 3. Validation of algorithms in different study sites as well as selective field data acquisition of leaf samples based on the estimations made by optical indices has been planned for the 1999 deployment. An evaluation of the predicative capability of the algorithms and methodology is planned through re-visits of the sites with 1999 field and airborne deployments.

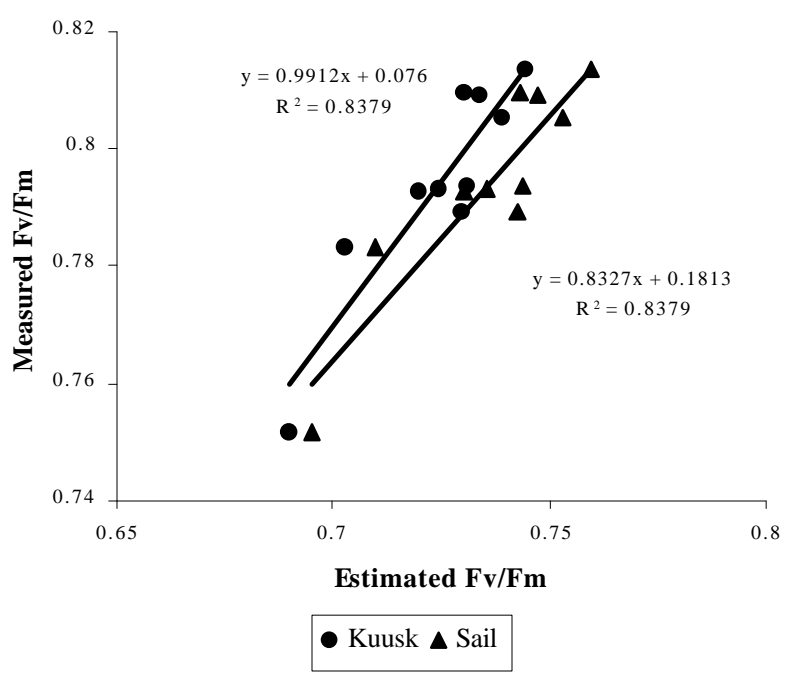

Figure 2.- Estimation of $\mathrm{Fv} / \mathrm{Fm}$ from CASI data using the DP21 $\left(\mathrm{D}_{\lambda_{0}} / \mathrm{D}_{703}\right)$ algorithm developed at leaf level through $S A I L$ and Kuusk CR models. Data from Acer saccharum M. study sites. 


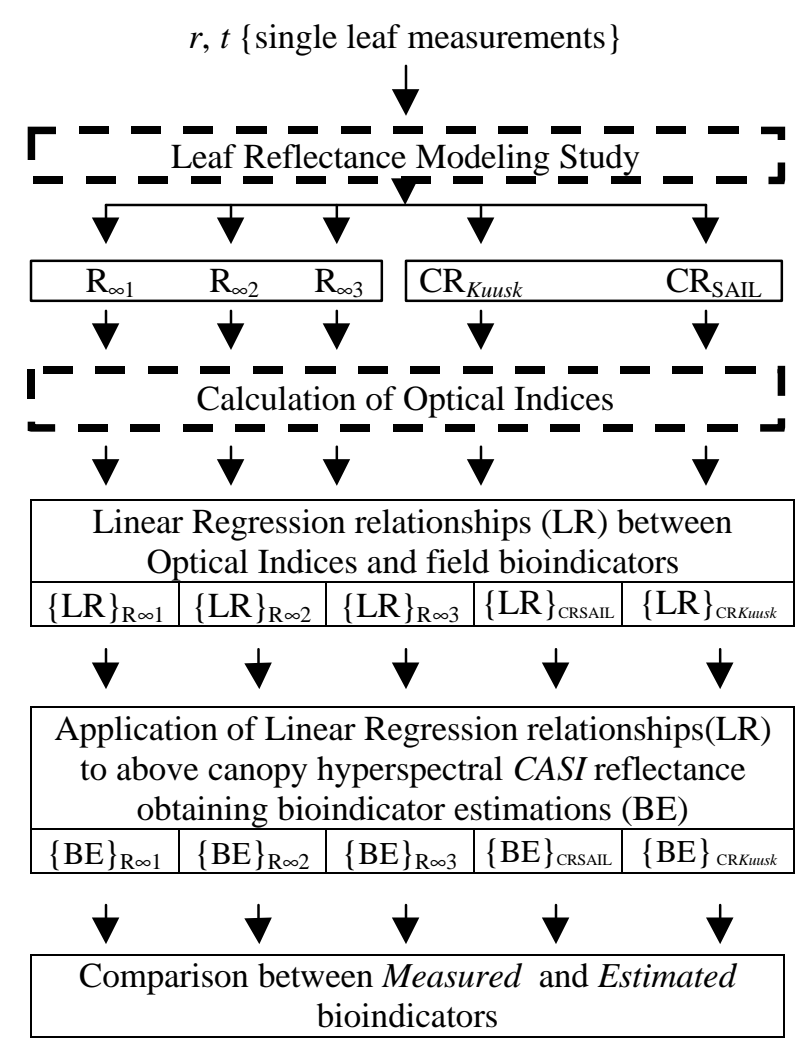

Figure 3. Schematic view of the overall analysis methodology followed in this study.

\section{CONCLUSIONS}

This study demonstrates a link between physiologicallybased indicators and optical indices from hyperspectral remote sensing for Acer saccharum M. study sites, as in previous studies. However, these results further suggest that leaf-level measurements of pigments and fluorescence along with leaf reflectance and transmittance can be used to produce algorithms to estimate these variables from abovecanopy spectral reflectance. The studies at three scales which progressively more closely represent the observed above-canopy reflectance spectra from the sites, show improvements in the estimation of leaf-based physiological indicators, such as chlorophyll- $a$, chlorophyll- $a \& b$, carotenoids and $\mathrm{Fv} / \mathrm{Fm}$ chlorophyll fluorescence. Canopy structure was shown to play an important role in this link, with SAIL and Kuusk models improving, in almost all cases, the estimation of the physiologically-based indicators, over the simpler optically-thick leaf simulations.

\section{ACKNOWLEDGEMENTS}

The authors wish to express our thanks especially to Denzil Irving (OFRI) for invaluable contributions toward the field programme, to Sebastian Martin (U. of Dundee, Scotland) and John Harron (CRESTech) for help with the single leaf measurements, and to Paul Shepherd and Lawrence Gray (CRESTech) for contributions toward successful airborne campaigns. Financial support provided by the Centre for Research in Earth and Space Technology (CRESTech), the Ontario Ministry of Natural Resources, the Canadian Forestry Service, and the Ministry of Environment and Energy is gratefully acknowledged.

\section{REFERENCES}

[1] Mohammed, G.H., P.H. Sampson, S.J. Colombo, T.L. Noland and J.R. Miller, Bioindicators of forest sustainability: Development of a forest condition rating system for Ontario, Ontario Forest Research Institute, Sault Ste. Marie, ON, Canada, 1997.

[2] Sampson, P.H., G.H. Mohammed, S.J. Colombo, T.L. Noland, J.R. Miller and P.J. Zarco-Tejada, Bioindicators of Forest Sustainability Progress Report, Ontario Forest Research Institute, Sault Ste. Marie, ON, Canada, 1998.

[3] Mohammed, G.H., W.D. Binder and S.L. Gillies, Chlorophyll fluorescence: A review of its practical forestry applications and instrumentation, Scand. J. For. Res., 10, pp. 383-410, 1995.

[4] Lillesaeter, O., Spectral reflectance of partly transmitting leaves: Laboratory measurements and mathematical modeling. Remote Sensing of the Environment, 12, pp. 247-254, 1982.

[5] Yamada, N. and S. Fujimura, Nondestructive measurement of chlorophyll pigment content in plant leaves from three-color reflectance and transmittance, Applied Optics, 30 (27), pp. 3964-3973, 1991.

[6] Miller J.R., M.D. Steven and T.H. Demetriades-Shah, Reflection of layered bean leaves over different soil backgrounds: measured and simulated spectra, International Journal of Remote Sensing, 13 (17), pp. 3273-3286, 1992.

[7] Hapke, B. Theory of Reflectance and Emittance Spectroscopy, Cambridge University Press, 1993.

[8] Verhoef, W., Light Scattering by Leaf Layers with Application to Canopy Reflectance Modeling: The SAIL Model, Remote Sensing of the Environment, 16, pp. 125-141, 1984.

[9] Kuusk, A. A computer-efficient plant canopy reflectance model. Computers \& Geosciences, 22 (2), pp. 149-163, 1996.

[10] Vogelmann, J.E., B.N. Rock and D.M. Moss, Red edge spectral measurements from sugar maple leaves, International Journal of Remote Sensing, Vol. 14 (8), pp. 1563-1575, 1993. 